between flat disks on a scale of Io centims. for a millimetre and 5 centims. to $I, 000$ cells.

From the curve thus laid down the following numbers were deduced :-

\begin{tabular}{|c|c|c|c|c|}
\hline \multirow{2}{*}{ EMF in volts. } & \multirow{2}{*}{$\begin{array}{c}\text { Striking } \\
\text { distance in } \\
\text { centimetres. }\end{array}$} & \multirow{2}{*}{$\begin{array}{l}\text { Difference of } \\
\text { potential per } \\
\text { centimetre. }\end{array}$} & \multicolumn{2}{|c|}{ Intensity of foree. } \\
\hline & & & $\begin{array}{l}\text { Electro- } \\
\text { magnetic. }\end{array}$ & $\begin{array}{l}\text { Electro- } \\
\text { static. }\end{array}$ \\
\hline$I, 000$ & 0.0205 & $\begin{array}{c}\text { yolts. } \\
48,770\end{array}$ & $4.88 \times 10^{12}$ & 163 \\
\hline 2,000 & 0.0430 & 46,500 & $4^{\circ} 65$, & 155 \\
\hline 3,000 & 0.0660 & 45,450 & 455, & 152 \\
\hline 4,000 & 0.0914 & 43,770 & $43^{8}$, & 146 \\
\hline 5,000 & 0.1176 & 42,5 Io & $4: 25$, & 142 \\
\hline 6,000 & 0.1473 & 40,740 & 4.07, & 136 \\
\hline 7,000 & 0.1800 & $3^{8,890}$ & 3.89, & 130 \\
\hline 8,000 & 0.2146 & 37,280 & 373 & 124 \\
\hline 9,000 & 0.2495 & $3^{6,070}$ & $3.6 \mathrm{r} \quad$ & 120 \\
\hline 10,000 & 0.2863 & 34,920 & 349, & 116 \\
\hline I I,, 00 & 0.3245 & 33,900 & 339 & I I 3 \\
\hline II,309 & 0.3378 & 33,460 & 335, & 112 \\
\hline
\end{tabular}

The remainder of the paper is chiefly occupied with the study of the phenomena of the electric arc under various conditions of distance, pressure, and potential; the results obtained support the view that the arc and the stratified discharge are merely modifications of the same phenomenon.

( $T$ o be continued.)

\section{A FOURTH STATE OF MATTER ${ }^{1}$}

$\mathrm{I}$ introducing the discussion on $\mathrm{Mr}$. Spottiswoode and Mr. Moulton's paper on the "Sensitive State of Vacuum Discharges," at the meeting of the Royal Society on April 15, Dr. De La Rue, who occupied the chair, good-naturedly challenged me to substantiate my statement that there is such a thing as a fourth or ultra-gaseous state of matter.

I had no time then to enter fully into the subject; nor was I prepared, on the spur of the moment, to marshal all the facts and reasons which have led me to this conclusion. But as I find that many other scientific men besides Dr. De La Rue are in doubt as to whether matter has been shown to exist in a state beyond that of gas, I will now endeavour to substantiate my position.

I will commence by explaining what seems to me to be the constitution of matter in its three states of solid, liquid, and gas.

I. First as to Solids:-These are composed of discontinuous molecules, separated from each other by a space which is relatively large-possibly enormous-in comparison with the diameter of the central nucleus we call molecule. These molecules, themselves built up of atoms, are governed by certain forces. Two of these forces I will here refer to-attraction and motion. Attraction when exerted at sensible distances is. known as gravitation, but when the distances are molecular it is called adhesion and cohesion. Attraction appears to be independent of absolute temperature; it increases as the distance between the molecules diminishes; and were there no other counteracting force the result would be a mass of molecules in actual contact, with no molecular movement whatever-a state of things beyond our conception-a state, too, which would probably result in the creation of something that, according to our present views, would not be matter.

This force of cohesion is counterbalanced by the movements of the individual molecules themselves, movements

x "On a Fourth State of Matter," in a letter to the Secretary of the Royal varying directly with the temperature, increasing and diminishing in amplitude as the temperature rises and falls. The molecules in solids do not travel from one part to another, but possess adhesion and retain fixity of position about their centres of oscillation. Matter, as we know it, has so high an absolute temperature that the movements of the molecules are large in comparison with their diameter, for the mass must be able to bear a reduction of temperature of nearly $300^{\circ} \mathrm{C}$. before the amplitude of the molecular excursions would vanish.

The state of solidity, therefore-the state which we are in the babit of considering par excellence as that of matter -is merely the effect on our senses of the motion of the discrete molecules among themselves.

Solids exist of all consistences, from the hardest metal, the most elastic crystal, down to thinnest jelly. A perfect solid would have no viscosity, i.e., when rendered discontinuous or divided by the forcible passage of a harder solid, it would not close up behind and again become continuous.

In solid bodies the cohesion varies according to some unknown factor which we call chemical constitution; hence each kind of solid matter requires raising to a different temperature before the oscillating molecules lose their fixed position with reference to one another. At this point, varying in different bodies through a very wide range of temperature, the solid becomes liquid.

II. In liquids the force of cohesion is very much reduced, and the adhesion or the fixity of position of the centres of oscillation of the molecules is destroyed. When artificially heated, the inter-molecular movements increase in proportion as the temperature rises, until at last cohesion is broken down, and the molecules fly off into space with enormous velocities.

Liquids possess the property of viscosity-that is to say, they offer a certain opposition to the passage of solid bodies; at the same time they cannot permanently resist such opposition, however slight, if continuously applied. Liquids vary in consistency from the hard, brittle, apparently solid pitch to the lightest and most ethereal liquid capable of existing at any particular temperature.

The state of liquidity, therefore, is due to inter-molecular motions of a larger and more tumultuous character than those which characterise the solid state.

III. In gases the molecules fly about in every conceivable direction, with constant collisions and enormous and constantly varying velocities, and their mean free path is sufficiently great to release them from the force of adhesion. Being free to move, the molecules exert pressure in all directions, and were it not for gravitation they would fly off into space. The gaseous state remains so long as the collisions continue to be almost infinite in number, and of inconceivable irregularity. The state of gaseity, therefore, is pre-eminently a state dependent on collisions. A given space contains millions of millions of molecules in rapid movement in all directions, each molecule having millions of encounters in a second. In such a case the length of the mean free path of the molecules is exceedingly small compared with the dimensions of the containing vessel, and the properties which constitute the ordinary gaseous state of matter, which depend upon constant collisions, are observed.

What, then, are these molecules? Take a single lone molecule in space. Is it solid, liquid, or gas? Solid it cannot be, because the idea of solidity involves certain properties which are absent in the isolated molecule. In fact, an isolated molecule is an inconceivable entity, whether we try, like Newton, to visualise it as a little hard spherical body, or, with Boscovich and Faraday, to regard it as a centre of force, or accept Sir William Thomson's vortex atom. But if the individual molecule is not solid, $\grave{a}$ fortior $i$ it cannot be regarded as a liquid or gas, for these states are even more due to inter-molecular collisions than is the solid state. The individual mole- 
cules, therefore, must be classed by themselves in a distinct state or category.

The same reasoning applies to two or to any number of contiguous molecules, provided their motion is arrested or controlled, so that no collisions occur between them; and even supposing this aggregation of isolated noncolliding molecules to be bodily transferred from one part of space to another, that kind of movement would not. thereby cause this molecular collocation to assume the properties of gas; a molecular wind may still be supposed to consist of isolated molecules, in the same way as the discharge from a mitrailleuse consists of isolated bullets.

Matter in the fourth state is the ultimate result of gaseous expansion. By great rarefaction the free path of the molecules is made so long that the hits in a given time may be disregarded in comparison to the misses, in which case the average molecule is allowed to obey its own motions or laws without interference; and if the mean free path is comparable to the dimensions of the containing vessel, the properties which constitute gaseity are reduced to a minimum, and the matter then becomes exalted to an ultra-gaseous state.

But the same condition of things will be produced if by any means we can take a portion of gas, and by some extraneous force infuse order into the apparently disorderly jostling of the molecules in every direction, by coercing them into a methodical rectilinear movement. This I have shown to be the case in the phenomena which cause the movements of the radiometer, and I have rendered such motion visible in my later researches on the negative discharge in vacuum tubes. In the one case the heated lamp-black and in the other the electrically excited negative pole supplies the force majeure which entirely or partially changes into a rectilinear motion the irregular vibration in all directions; and according to the extent to which this onward movement has replaced the irregular motions which constitute the essence of the gaseous condition, to that extent do I consider that the molecules have assumed the condition of radiant matter.

Between the third and the fourth states there is no sharp line of demarcation, any more than there is between the solid and liquid states, or the liquid and gaseous states; they each merge insensibly one into the other. In the fourth state properties of matter which exist even in the third state are shown directly, whereas in the state of gas they are only shown indirectly, by viscosity and so forth.

The ordinary laws of gases are a simplification of the effects arising from the properties of matter in the fourth state; such a simplification is only permissible when the mean length of path is small compared with the dimensions of the vessel. For simplicity's sake we make abstraction of the individual molecules, and feign to our imagination continuous matter of which the fundamental properties-such as pressure varying as the density, and so forth-are ascertained by experiment. A gas is nothing more than an assemblage of molecules contemplated from a simplified point of view. When we deal with phenomena in which we are obliged to contemplate the molecules individually, we must not speak of the assemblage as gas.

These considerations lead to another and curious speculation. The molecule-intangible, invisible, and hard to be conceived-is the only true matter, and that which we call matter is nothing more than the effect upon our senses of the movements of molecules, or, as John Stuart Mill expresses it, "a permanent possibility of sensation." The space covered by the motion of molecules has no more right to be called matter than the air traversed by a rifle bullet can be called lead. From this point of view, then, matter is but a mode of motion; at the absolute zero of temperature the inter-molecular movement would stop, and although something retaining the properties of inertia and weight would remain, matter, as we know it, would cease to exist.

\section{NOTES}

THE Council of the Society of Arts have awarded the Albert Medal of the Society of the present year to James Prescott Joule, LL.D., D.C.L., F.R.S., "for having established, after most laborious research, the true relation between heat, electricity, and mechanical work, thus affording to the engineer a sure guide in the application of science and industrial pursuits.' The medal was delivered to Dr. Joule by the Prince of Wales on Tuesday, when Sir William Thomson received the medal awarded him by the Society in 1878 .

THE Paris Academy of Sciences has awarded the Monthyon Prize to M. Camille Flammarion for his new work entitled "Astronomie Populaire." It is a large 4to volume, with magnificent engravings, which was sold in Ioo penny parts. The sale in the first year of publication reached 40,000 copies.

IT is stated that M. Coggia, Astronomer to the Marseilles Observatory, will be appointed Director of the Algiers Observatory, where no observations at all have been made since its creation in 1864 by Marshal Pelissier.

THE University of Oxford has conferred the degree of D.C.L on Prof. Sylvester and Mr. Lister, the eminent surgeon.

ON Saturday, May 5, the local committee of the French Association for the Advancement of Science met at Rheims, where the next meeting is to be held in August. An exposition of local industry and archæology will be held. Arrangements have been made for excursions connected with the congress, the more notable of which will be to the Han Grottoes, which are situated in Belgium. Nothing has been arranged yet as to the lectures to be delivered.

THe new Principal of the Royal Agricultural College, Cirencester, the Rev. J. B. McLellan, has started a scheme of con. gresses or conferences which may prove of considerable value to agriculture. On Friday, the $5^{\text {th }}$ inst., a goodly number of old Cirencester students and protessors, as well as local agriculturists, met in the College Hall to discuss important agricultural questions. The morning session was occupied with the subject of cattle diseases; the afternoon was devoted to agricultural stations and research. If the papers introducing the subjects were not of a very high order, it may at least be conceded that the discussions which followed brought out some sound information and advice. If such congresses as this at Cirencester help to draw public attention to the need for some new departure in modern and scientific agriculiure, and if they stimulate those interested in farming to look to the College as the central authority on a subject which that institution must learn to handle adequately, then we predict for them a substanial success.

THE annual conference at the Society of Arts on the laws, administration and inspection with regard to public health was opened on Thursday under the presidency of Mr. Stansfeld, M.P. The committee had drawn up a programme of subjects for discussion, which were grouped under the following headings :I. Administrative Organisation: 2. Amendment of the Law : 3. Sanitary Inspection and Classification of Dwellings: 4. Further suggestions by Sanitary Anthorities. In the discussion on Thursday the chairman, in opening the proceedings, pointed out the desirability of an "inquiry office" being established in connection with the Local Government Board, at which local anthorities might obtain information based on experience. One great hope for the future was that the teaching of the laws of health to children was gradually spreading. The conference was resumed on Friday. In reference to the third heading, the following resolution was put to the meeting:- "That it is expedient that the Metropolitan Board of Works within the metropolis, and the County Board within each county, should 